\title{
Investigation on Photodecomposition of Standardised Ethyl Acetate Fraction of Katha
}

\author{
Pankaj Sharma*
}

\section{Pankaj Sharma*}

Department of Pharmacy, Institute of Pharmacy and Research, S.J.J.T.U, Vidyanagari, Jhunjuhunu, Rajasthan, INDIA.

\section{Correspondence}

\section{Mr. Pankaj Sharma}

Research Scholar, Department of Pharmacy, Institute of Pharmacy and Research, S.J.J.T University, Jhunjhunu, Rajasthan - 333001, INDIA

Phone no: +918626976382

E mail: pankajsharmadrugs@gmail.com

History

- Submission Date: 04-03-2020;

- Review completed: 15-03-2020;

- Accepted Date: 11-04-2020.

\section{DOI : 10.5530/pj.2020.12.117}

Article Available online http://www.phcogj.com/v12/i4

\section{Copyright}

(C) 2020 Phcogj.Com. This is an openaccess article distributed under the terms of the Creative Commons Attribution 4.0 International license.

\begin{abstract}
Objective: The present study delves into photodecomposition of a standardised ethyl acetate fraction of Katha and manifest how the antioxidant potential degrades exponentially with time. Methods: Coarsely dried heart wood of Acacia catechu (L.f.) Willd. was treated with $10 \%$ hydro-alcoholic solution to obtain Katha as final product. The powdered Katha was standardised via pharmacognostic parameters and further subjected to soxhlet extraction using ether, ethyl acetate and ethanol to obtain different extracts/fractions. Phytochemical investigations were carried out to screen polyphenols (tannins) of interest which later were confirmed by thin layer chromatography (TLC). Photodecomposition of ethyl acetate fraction with respect to its in-vitro antioxidant potential using DPPH and nitric oxide scavenging assay was determined at $0 \mathrm{~h}, 4$ $\mathrm{h}, 8 \mathrm{~h}, 12 \mathrm{~h}, 16 \mathrm{~h}, 20 \mathrm{~h}$ and $24 \mathrm{~h}$ of $250,500,750$ and $1000 \mu \mathrm{g} / \mathrm{ml}$ concentrations respectively. Ethyl acetate fraction conceded the highest amount of polyphenols. Results: The extract was found to be unstable at room temperature and displayed a quick change in colour from light orange to deep dark orange within few hours, which also abide by its decreasing antioxidant activity exponentially with time. Antioxidant potential was observed in the following order in dose dependant manner: $0 \mathrm{~h}>4 \mathrm{~h}>8 \mathrm{~h}>12 \mathrm{~h}>16 \mathrm{~h}>20 \mathrm{~h}>24 \mathrm{~h}$. Conclusion: Moreover, published literature should have not mentioned the age of extract they have used for their study, which may explain the wide differences in the observations reported with this plant.

Key words: Acacia catechu, DPPH, Antioxidant, Nitric oxide scavenging, Free radical, Katha.
\end{abstract}

\section{INTRODUCTION}

The use of herbal medicines has become a global subject with medical and economic ramifications over the past few decades. ${ }^{1}$ Acacia catechu (L.f.) Willd. known by the name 'khadira' in Ayurveda belongs to Leguminosae family. ${ }^{2}$ The plant is a small moderate sized tree about 10-13 meter height extensively scattered throughout India. ${ }^{3}$ The medicinal significance of this plant is reflected by the use of leaves, bark and heartwood in several Ayurvedic formulations for thousand years. ${ }^{4}$ Heartwood of A. catech $u$ has more potent medicinal activity in comparison to its leaves and bark. ${ }^{5}$ The heartwood extract of $A$. catech $u$ has been reported to have various pharmacological effects like antioxidant, ${ }^{6}$ anti-inflammatory, ${ }^{7}$ antimicrobial, ${ }^{8}$ immunomodulatory, ${ }^{9}$ antipyretic, hypoglycaemic, ${ }^{10}$ anti-diarrhoeal and hepatoprotective ${ }^{11}$ etc. The plant contains polyphenols like tannins, flavonoids alongwith carbohydrates and proteins. ${ }^{12}$ The major constituents of the plant includes catechin (-), epicatechin, epigallocatechin, epicatechingallate and epigallocatechin gallate. Other constituents include rocatechin, phloroglucin, protocatechuic acid, quercetin, poriferasterol glucosides, lupenone, lupeol, procyanidin AC, kaempferol, dihydrokaemferol, toxifolin, (+)-afzelchin gum and minerals. ${ }^{13}$ The heartwood of this plant is known by the name 'Katha' which is well known for its diverse pharmacological properties. ${ }^{14,15}$ In the present study the stability of standardised ethyl acetate extract and changes in antioxidant potential was investigated through in-vitro studies as illustrated in Figure 1. Storage conditions were already reported to exert marked influence over chemical composition of crude drugs. ${ }^{16,17}$ The aim of this study was to determine antioxidant capacity of ethyl acetate fraction of Katha obtained from the heart wood of plant $A$. catechu and to access its photodecomposition based on temperature and storage conditions.

\section{MATERIALS AND METHODS}

\section{Plant material}

The heartwood of the plant was collected in the month of November 2019 from Hamirpur district of Himachal Pradesh, India which further was authenticated by Raw material herbarium and museum, NISCAIR, New Delhi, India. A voucher specimen of the plant was preserved in the herbarium for reference (NISCAIR/RHHD/ Consult/2019/3465-66).

\section{Preparation of plant extract (Katha)}

The heartwood of $A$. catech $u$ was dried at room temperature $\left(25 \pm 2^{\circ} \mathrm{C}\right)$ for four consecutive weeks and pulverised. Katha was obtained from the heartwood of $A$. catechu by boiling the chips of heartwood with $10 \%$ hydro-alcoholic solution. ${ }^{18}$

\section{Standardisation of katha}

The specimen was processed for pharmacognostic standardisation viz morphological studies, powder 


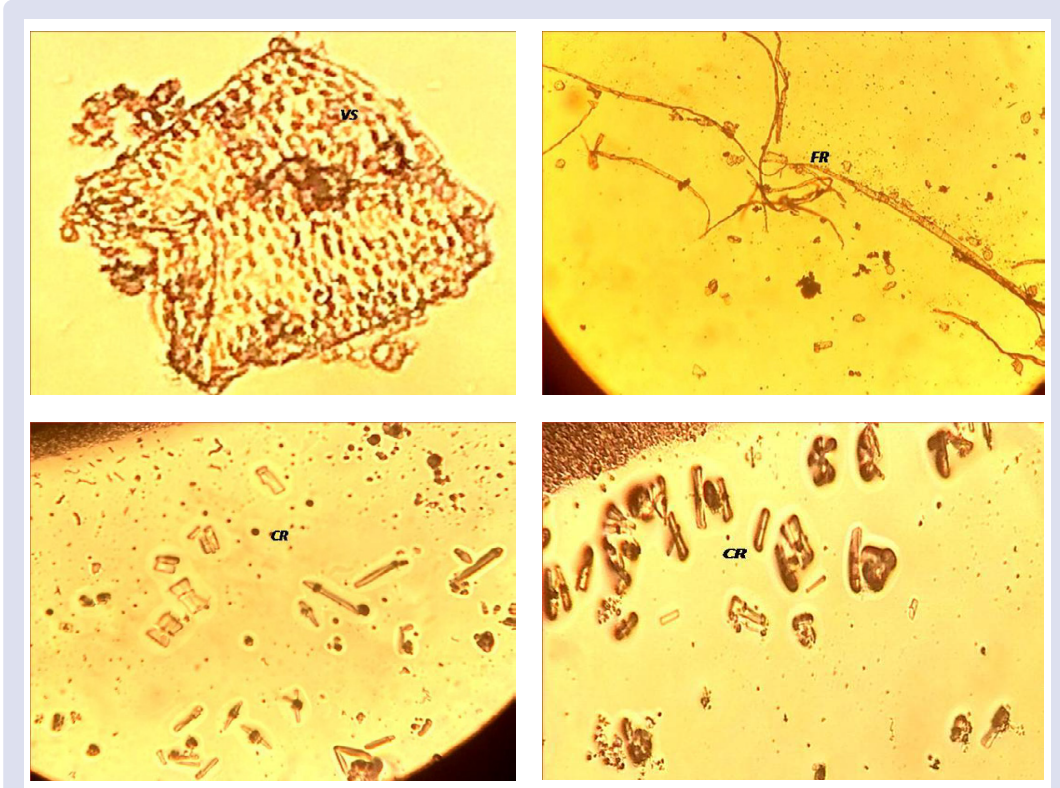

Figure 1: Microscopic characteristics of Katha.VS: vessels, CR: crystals, FR: fibres.

microscopy, ash value determination, florescence analysis and loss on drying. Each extract was then screened for secondary metabolites. Presence of active antioxidant compound was confirmed with the help of thin layer chromatography by using desired mobile and stationary phases. These parameters are considered essential in quality control of the crude drugs. ${ }^{19}$

\section{Soxhlation of katha}

Katha chips obtained from heartwood of $A$. catechu is powdered and extracted by successive solvent extraction technique using soxhlet apparatus. $100 \mathrm{~g}$ of coarsely powdered drug was allowed to get extracted with different solvents in order of increasing polarity viz. ether, ethyl acetate and ethanol.

\section{Quantitative phytochemical screening}

Quantitative phytochemical screenings of ethyl acetate fraction of Katha were performed as per standard protocols to detect the amount of total phenols and total flavonoids in ethyl acetate fraction.

\section{Determination of total phenolic content}

Folin-Ciocalteu reagent was used to evaluate the total phenolic content of the extract using gallic acid as standard. ${ }^{20}$ Standard curve of Gallic acid was prepared by taking 500, 250, 125, 62.5, 31.25 and $15.625 \mu \mathrm{g} / \mathrm{ml}$ concentrations. Procedure for determining absorption of various concentrations is same as follows for extract fractions. All the samples were subjected to temperature of $60^{\circ} \mathrm{C}$ on water bath for $1 \mathrm{~h}$ followed by cooling to room temperature. $400 \mu \mathrm{L}$ of this solution was transferred into the test tube containing $1.6 \mathrm{~mL}$ of sodium carbonate (7.5\% in deionized water) and $2 \mathrm{~mL}$ of Folin Ciocalteu reagent $(0.1 \%$ in deionized water). Further all the samples were incubated for $1 \mathrm{~h}$ at room temperature. Absorbance was measured at $525 \mathrm{~nm}$ using UV Spectrophotometer. All the readings were taken in triplicate. Total phenolic content was expressed in $\mathrm{mg}$ Gallic acid equivalent (GAE) per gram of extracts, using calibration curve.

\section{Estimation of flavonoid content}

Most commonly used method to determine total flavonoids contents by taking Quercetin as standard..$^{21}$ Different concentration of extract and standard was prepared as above and 100, 50, 25, $12.5 \mu \mathrm{g} / \mathrm{ml}$ extract and standard was added to the test tube containing $75 \mu \mathrm{L}$ of $5 \% \mathrm{NaNO} 2$ solution. Mixture was allowed to stand for 10 minute. $150 \mu \mathrm{L}$ of a $10 \%$ $\mathrm{AlCl} 3.6 \mathrm{H} 2 \mathrm{O}$ solution was then added to every sample and were allowed to stand for 5 minutes. Further $0.5 \mathrm{~mL} \mathrm{NaOH}(1 \mathrm{M})$ and $2.5 \mathrm{~mL}$ of distilled water was added to each sample. Absorbance was measured at $510 \mathrm{~nm}$ using UV Spectrophotometer. All the observations were taken in triplicate. Total flavonoid content was calculated as mg Querctine equivalent $(\mathrm{QE}) / \mathrm{g}$ by using the linear regression equation obtained for Quercetin.

\section{Antioxidant activity}

In the present study, two commonly used antioxidant evaluation methods such as DPPH radical scavenging activity and Nitric oxide radical scavenging assay were selected to determine the antioxidant potential of ethyl acetate fraction of Katha.

\section{Determination of Free Radical Scavenging Activity by DPPH Method}

DPPH radical scavenging activity of ethyl acetate fraction of Katha was determined according to the standard method with slight alteration. The reaction mixture containing $500,1000 \mu \mathrm{g} / \mathrm{ml}$ of extract concentration and $2 \mathrm{ml}$ of DPPH ( $0.1 \mathrm{Mm}$ in methanol) was allowed to stand for 15 minutes in dark at room temperature. Absorbance was measured using double beam UV-VIS spectrophotometer (shimadzu-1601) and tested against the blank. The scavenging potential was calculated by using the following equation. ${ }^{22}$

$\%$ Inhibition $=\frac{B^{\circ}-B^{1}}{B^{\circ}} X 100$

Where $\mathrm{B}^{\circ}$ is the absorbance of negative control

$\mathrm{B}^{\mathrm{I}}$ is the absorbance of the reaction mixture

Determination of Free Radical Scavenging Activity by Nitric Oxide Radical Method

Griess reagent was prepared by mixing same amounts of $1 \%$ sulphanilamide in $2.5 \%$ phosphoric acid and $0.1 \%$ naphthylethylene diamine dihydrochloride in $2.5 \%$ phosphoric acid. Ethyl acetate extract 
was added with similar volume of freshly prepared sample. Nitric oxide radical so generated was found to be inhibited by ethyl acetate extract at different concentrations. Decolouration due to reaction by polyphenols in ethyl acetate fraction with the nitric oxide free radical was then measured spectrophotometrically. The percentage inhibition of ethyl acetate extract and standard was recorded. All the experiments related to antioxidant activity were performed in triplicate..$^{23}$

\section{RESULTS}

\section{Pharmacognostic data}

Katha occurs in pieces of variable sizes of 4 to $4.5 \mathrm{~cm}$ in length and 3.5 to $4.5 \mathrm{~cm}$ in breath, yellowish brown in colour, fracture is hard, characteristic odour with astringent taste. Powder microscopy of Katha revealed the presence of acicular type crystals, fibers and pitted vessels as shown in Figure 1. Successive extractive values with ether, ethyl acetate and ethanol were found as $1.2 \% \mathrm{w} / \mathrm{w}, 4.5 \% \mathrm{w} / \mathrm{w}$ and 3.5 $\% \mathrm{w} / \mathrm{w}$ respectively Table 1 . Total ash and acid insoluble ash value was found to be $11.5 \% \mathrm{w} / \mathrm{w}, 0.68 \% \mathrm{w} / \mathrm{w}$ which confirms the presence of inorganic content in the drug. Moisture content of the drug was found to be between $9-13 \%$ w/w. On exposure to UV light Katha showed dark brown fluorescence.

\section{Percentage yield of katha}

Different extracts were obtained upon successively treated the sample (Katha) with different solvents as mentioned in Table 1.

\section{Phytochemical Studies}

Preliminary phytochemical screening of ether, ethyl acetate and ethanolic extract of Katha showed the presence of tannins, flavonoids, saponins and triterpenes as shown in Table 2 but the main allure of screening was presence of polyphenols (tannins, flavonoids) in ethyl acetate extract. Tannins reported in this plant have already been documented to exhibit pharmacological as well as physiological properties (6-11). Furthermore, ethyl acetate extract of Katha is having pink colour with no odour and obtained as fine powder as shown in Figure 2a. Ethyl acetate extract is highly soluble in methanol, ethyl acetate, slightly soluble in benzene, petroleum ether and insoluble in water. Melting point of the extract was found to be between $150-210^{\circ} \mathrm{C}$ and in UV light extract showed magenta colour fluorescence.

\section{TLC profile}

TLC of ethyl acetate extract on precoated TLC plates Merck GF-254 using Chloroform: Methanol: Water (8:2:0.5) as mobile phase showed four different spots at $\mathrm{Rf} 0.2,0.4,0.5,0.6$ after detection with vanillin sulphuric acid reagent and in UV-366 nm as shown in Figure $2 \mathrm{~b}$ which were later identified as epicatechin/catechin, epigallocatechin, querecetin and procyanidin AC respectively.

\section{Quantitative phytochemical screening}

The standard curve of Gallic acid obtained at different concentration $(\mu \mathrm{g} / \mathrm{ml}) 500,250,125,62.5,31.25 \& 15.625$ respectively. Total phenolic content of the extract fractions was calculated in terms of mg GAE per

Table 1: Extractive yield (\%).

\begin{tabular}{cc}
\hline Extract & \% Extractive value (w/w) \\
\hline Katha (Sovent-10\% hydro alcoholic solution) & 11.87 \\
Ether & 1.2 \\
Ethyl acetate & 4.5 \\
Ethanol & 3.5 \\
\hline
\end{tabular}

Table 2: Preliminary phytochemical screening of extract.

\begin{tabular}{ccccc}
\hline Metabolite & Test & EE & ETE & EHT \\
\hline Tannins & Gelatin & + & +++ & ++ \\
Flavonoids & Lead acetate, Alkaline reagent & ++ & +++ & + \\
Triterpenes & Liebermann burchard & + & + & + \\
Glycosides & Modified borntagers & - & - & + \\
Saponins & Froth formation & + & & ++ \\
Steroids & Salkowski & - & - & - \\
Alkaloids & Mayers and wagner reagent & - & - & - \\
\hline
\end{tabular}

+++ active constituent is highly present, ++ active constituent is moderately present, + active constituent is slightly present, active constituent absent, EE: Ether extract, ETC: Ethyl acetate extract, EHT: Ethanol extract.

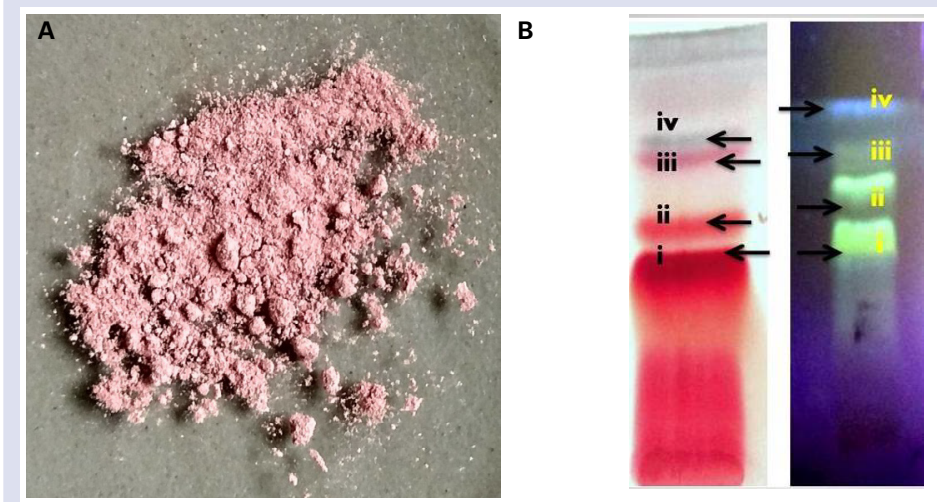

Figure 2: A. Ethyl acetate extract of Katha. B. TLC of ethyl acetate extract of Katha. 
gram of extracts. Total phenolic contents were calculated using linear regression equation $\mathrm{y}=0.003 \mathrm{X}+0.033$ at $\mathrm{R}^{2}=0.998$. Total phenolic content in Ethyl acetate extract were calculated to be $96.4 \mathrm{mg} \mathrm{GAE} /$ gram of extract fractions respectively. In another side estimation of total flavonoids content, the standard curve of Querctine was plotted at different concentration $(\mu \mathrm{g} / \mathrm{ml}) 100,50,25,12.5 \& 6.75$ respectively. Linear regression was applied to obtained curve. Total flavonoid content were then calculated from equation $\mathrm{y}=0.009 \mathrm{x}-0.014$ at $\mathrm{R}^{2}=0.999$ in terms of $\mathrm{mg} \mathrm{QE} / \mathrm{g}$ of extract fraction. Total flavanoid content in Ethyl acetate extract were calculated to be $46.43 \mathrm{mg} \mathrm{QE} / \mathrm{g}$ of extract fractions.

Determination of free radical scavenging activity by DPPH method

DPPH radical showed a strong absorption maximum at $517 \mathrm{~nm}$ (purple). In presence of antioxidant the colour reaction takes place. DPPH free radical scavenging activity of ethyl acetate extract of Katha at various concentrations $500 \mu \mathrm{g} / \mathrm{ml}$ and $1000 \mu \mathrm{g} / \mathrm{ml}$ was determined by taking sample with different storage conditions as shown in Figure 3 and Table 3. The first sample selected was kept at light under ordinary room temperature and the other sample was stored in dark under controlled environment.

\section{Determination of free radical scavenging activity by nitric oxide radical method}

Percentage free radical scavenging was plotted against concentration of the extracts as shown in Figure 4. The Nitric oxide free radical scavenging activity of ethyl acetate extract of Katha at various concentrations viz $500 \mu \mathrm{g} / \mathrm{ml}$ and $1000 \mu \mathrm{g} / \mathrm{ml}$ was determined by taking sample with different storage conditions Table 4 . The first sample was kept at light under ordinary room temperature and the second sample was stored in dark under controlled conditions. It was observed that the sample placed in dark and in controlled conditions does not show any change in the scavenging potential whereas the sample placed in light, under ordinary temperature undergoes deterioration exponentially with time.

Table 3: Photo-decomposition of the ethyl acetate extract of Katha by DPPH.

\begin{tabular}{ccccc}
\hline Time $(\mathbf{h})$ & $\%$ AA & $\%$ BB & $\%$ CC & $\%$ DD \\
\hline 0 & $11.56 \%$ & $11.56 \%$ & $21.68 \%$ & $21.67 \%$ \\
4 & $11.16 \%$ & $11.53 \%$ & $19.93 \%$ & $21.66 \%$ \\
8 & $10.64 \%$ & $11.57 \%$ & $18.02 \%$ & $21.65 \%$ \\
12 & $10.01 \%$ & $11.54 \%$ & $16.35 \%$ & $21.68 \%$ \\
16 & $9.36 \%$ & $11.56 \%$ & $15.98 \%$ & $21.64 \%$ \\
20 & $8.96 \%$ & $11.58 \%$ & $14.69 \%$ & $21.66 \%$ \\
24 & $7.74 \%$ & $11.59 \%$ & $12.92 \%$ & $21.65 \%$ \\
\hline
\end{tabular}

$\%$ AA: $500 \mu \mathrm{g} / \mathrm{ml}$ in presence of light, $\%$ BB: $500 \mu \mathrm{g} / \mathrm{ml}$ in dark, $\%$ CC: $1000 \mu \mathrm{g} / \mathrm{ml}$ in presence of light, $\% \mathrm{DD}: 1000 \mu \mathrm{g} / \mathrm{ml}$ in dark.

Table 4: Photo-decomposition of ethyl acetate extract of Katha by Nitric oxide scavenging method.

\begin{tabular}{ccccc}
\hline Time (h) & \% AA & \% BB & \% CC & $\%$ DD \\
\hline 0 & $17.56 \%$ & $17.56 \%$ & $28.93 \%$ & $28.94 \%$ \\
4 & $16.25 \%$ & $17.53 \%$ & $26.43 \%$ & $28.95 \%$ \\
8 & $15.69 \%$ & $17.54 \%$ & $25.45 \%$ & $28.92 \%$ \\
12 & $14.68 \%$ & $17.55 \%$ & $22.35 \%$ & $28.93 \%$ \\
16 & $12.08 \%$ & $17.54 \%$ & $19.98 \%$ & $28.94 \%$ \\
20 & $11.35 \%$ & $17.55 \%$ & $18.69 \%$ & $28.96 \%$ \\
24 & $10.97 \%$ & $17.56 \%$ & $16.92 \%$ & $28.95 \%$ \\
\hline
\end{tabular}

$\%$ AA: $500 \mu \mathrm{g} / \mathrm{ml}$ in presence of light, \% BB: $500 \mu \mathrm{g} / \mathrm{ml}$ in dark, \% CC: $1000 \mu \mathrm{g} / \mathrm{ml}$ in presence of light, $\%$ DD: $1000 \mu \mathrm{g} / \mathrm{ml}$ in dark.

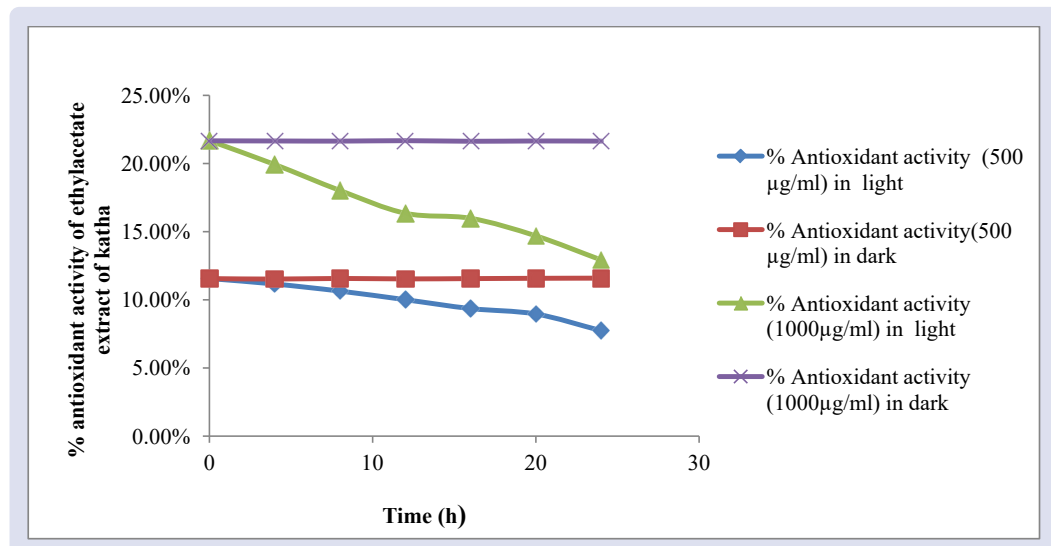

Figure 3: Percentage deterioration in antioxidant activity in DPPH free radical scavenging assay. 


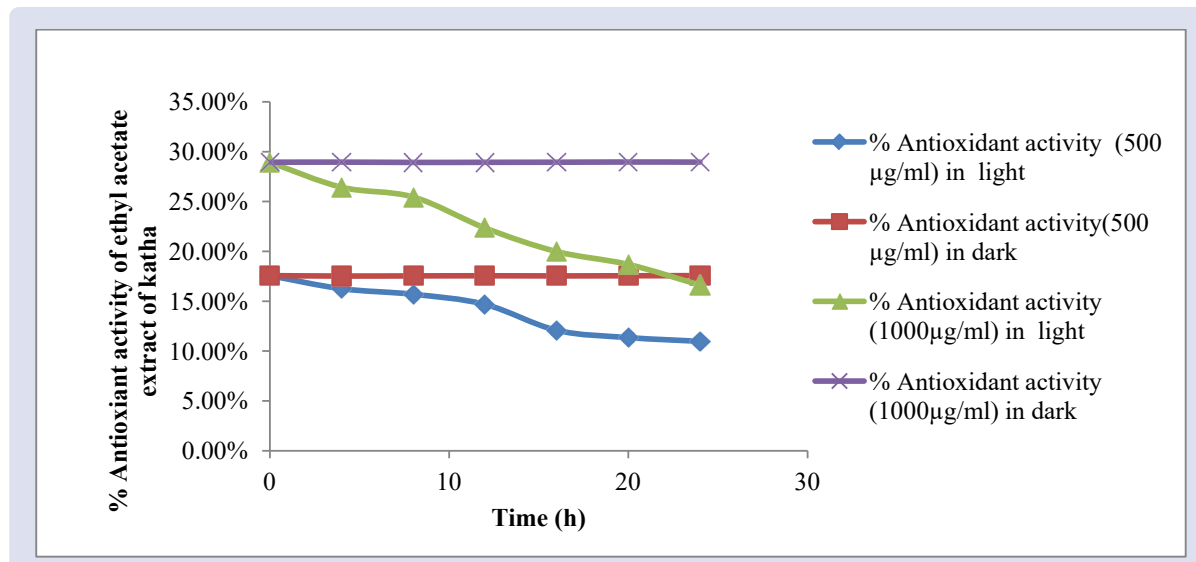

Figure 4: Percentage deterioration in antioxidant activity in nitric oxide scavenging assay.

\section{DISCUSSION}

Katha obtained by boiling the heartwood of A. catechu with $10 \%$ hydro-alcoholic solution resulted in increase in the percentage yield value by $10 \% \mathrm{w} / \mathrm{w}$. In chromatographic studies four active substances were identified on the basis of their respective $\mathrm{Rf}$ values. But the major concern of this study was to determine the photo-decomposition of ethyl acetate extract at different storage conditions. The extract is highly unstable in its solution form and its antioxidant potential degrades exponentially with time. For evaluating its antioxidant potential two methods were used (DPPH free radical scavenging and nitric oxide free radical scavenging). Results showed that antioxidant potential degrades in dose dependant manner: $0 \mathrm{~h}>4 \mathrm{~h}>8 \mathrm{~h}>12 \mathrm{~h}>16 \mathrm{~h}>20 \mathrm{~h}>24 \mathrm{~h}$, respectively. As the duration of storage of extract at room temperature under ordinary conditions increased, the antioxidant potential showed a marked decline. It is pertinent here to mention that the sample (ethyl acetate extract) placed in dark under controlled conditions does not show any change in the scavenging potential whereas the sample placed in light, under ordinary temperature conditions undergoes deterioration augmented with time.

\section{CONCLUSION}

Standardised ethyl acetate extract of Katha was found to be highly unstable in its solution form and showed exponential decline in antioxidant potential with time. Therefore, for the experimental purpose, it should be preserved properly to avoid photodecomposition and to alleviate chances of deviation. The overall outcome of this study can be considered as very promising in establishing stability profile of plant extract with respect to storage conditions and time. Hence, from this study it might be postulated that plant extracts containing polyphenols are highly sensitive and undergoes photo-degradation exponentially with time so special care should be given while handling these plant extracts which otherwise might causes deviation in the therapeutic profile of the drugs like in our case antioxidant activity.

\section{ACKNOWLEDGMENTS}

Authors extend thanks to Dr. Vineet Mehta \& Mr. Vikrant Arya Assistant Professor Government College of Pharmacy Rohru for his technical support to carry out this research study.

\section{ETHICS APPROVAL AND CONCENT TO PARTICI- PATE}

No applicable.

\section{HUMAN AND ANIMAL RIGHTS}

No animals/Humans were used for studies that are base of this research.

\section{CONCENT FOR PUBLICATION}

Not applicable.

\section{CONFLICTS OF INTEREST}

The authors declare no conflicts of interest, financial or otherwise.

\section{REFERENCES}

1. Ekor M. The growing use of herbal medicines: issues relating to adverse reactions and challenges in monitoring safety. Frontiers in Pharmacology. 2014;4:1777.

2. Stohs SJ, \& Bagchi D. Antioxidant, anti-inflammatory, and chemoprotective properties of Acacia catechu heartwood extracts. Phytotherapy Research. 2015;29:818-24.

3. Mandal N, Ghate N, Hazra B, Sarkar R. Heartwood extract of Acacia catechu induces apoptosis in human breast carcinoma by altering bax/bcl-2 ratio. Pharmacognosy Magazine. 2014;10:27.

4. Aggarwal B, Prasad S, Reuter S, Kannappan R, Yadav V, Park B, et al. Identification of Novel Anti-inflammatory Agents from Ayurvedic Medicine for Prevention of Chronic Diseases: "Reverse Pharmacology" and "Bedside to Bench" Approach. Current Drug Targets. 2011;12:1595-653.

5. Patil A, Manisha M. Comparative evaluation of oxidative stress modulating and DNA protective activities of aqueous and methanolic extracts of Acacia catechu. Medicines. 2017;4:65.

6. Saha MR, Dey P, Begum S, De B, Chaudhuri TK, Sarker DD, et al. Effect of Acacia catechu (L.f.) Willd. on Oxidative Stress with Possible Implications in Alleviating Selected Cognitive Disorders. PLoS ONE. 2016;11:e0150574.

7. Burnett BP, Jia Q, ZhaoY, Levy RM. A medicinal extract of Scutellaria baicalensis and Acacia catechuacts as a dual inhibitor of cyclooxygenase and 5-lipoxygenase to reduce inflammation. Journal of Medicinal Food. 2007;10:442-451.

8. Joshi S, SubediYP, Paudel SK. Antibacterial and antifungal activity of heartwood of Acacia catechu of Nepal. Journal of Nepal Chemical Society. 2011;27:94-9.

9. Sunil, MA, Sunitha VS, Radhakrishnan EK, Jyothis M. Immunomodulatory activities of Acacia catechu, a traditional thirst quencher of South India. Journal of Ayurveda and Integrative Medicine. 2018.

10. Ikarashi N, Toda T, Okaniwa T, Ito K, Ochiai W, Sugiyama K. Anti-Obesity and Anti-Diabetic Effects of Acacia Polyphenol in Obese Diabetic KKAy Mice Fed High-Fat Diet. Evidence-Based Complementary and Alternative Medicine. 2011;1-10.

11. Micucci M, Gotti R, Corazza I, Tocci G, Chiarini A, De Giorgio M, et al. Newer Insights into the Antidiarrheal Effects of Acacia catechuWilld. Extract in Guinea Pig. Journal of Medicinal Food. 2017;20:592-600.

12. Lay MM, Karsani SA, Mohajer S, Abd Malek SN. Phytochemical constituents, nutritional values, phenolics, flavonols, flavonoids, antioxidant and cytotoxicity studies on Phaleria macrocarpa (Scheff.) Boerl fruits. BMC Complementary and Alternative Medicine. 2014;14:152.

13. Meera B, Chander J, Kalidhar SB. A Review on the chemistry and bioactivity of Acacia Spp. Journal of Medicinal and Aromatic Plants Science. 2005;27:51-90.

14. Survase SA, Raut SD. Ethnobotanical study of some tree medicinal plants in Marathwada, Maharashtra. Journal of Ecobiotechnology. 2011;3:17-21.

15. Hazra B, Sarkar R, Biswas S, Mandal N. The Antioxidant, Iron Chelating and DNA Protective Properties of $70 \%$ Methanolic Extract of "Katha" (Heartwood extract of Acacia catechu). Journal of Complementary and Integrative Medicine. 2010;7:1335 
16. Ali A, Chong C, Mah S, Abdullah L, Choong T, Chua B. Impact of Storage Conditions on the Stability of Predominant Phenolic Constituents and Antioxidant Activity of Dried Piper betle Extracts. Molecules. 2018;23:484.

17. Colla LM, Bertol CD, Ferreira DJ, Bavaresco J, Costa AV, Bertolin TE. Thermal and photo-stability of the antioxidant potential of Spirulina platensis powder. Brazilian Journal of Biology. 2016;77:332-9.

18. Sasidharan S, Chen Y, Saravanan D, Sundram KM, and Latha LY. Extraction, isolation and characterization of bioactive compounds from plants extracts. African Journal of Traditional, Complementary and Alternative Medicines. 2011;8:1-10.

19. Birdi T, Gupta $P$, Daswani $P$. Approaches in fostering quality parameters for medicinal botanicals in the Indian context. Indian Journal of Pharmacology. $2014 ; 46: 363$
20. Chun OK, Kim DO. Consideration on equivalent chemicals in total phenolic assay of chlorogenic acid-rich plums. Food Research International. 2004;37(4):337-42

21. Zhishen J, Mengcheng T, Jianming W. The determination of flavonoid contents in mulberry and their scavenging effects on superoxide radicals. Food Chemistry. 1999;64(4):555-9.

22. Aksoy L, Kolay E, Agilonu Y, Aslan Z, Kargioglu M. Free radical scavenging activity, total phenolic content, total antioxidant status, and total oxidan status of endemic Thermopsis turcica. Saudi Journal of Biological Sciences. 2013;20:235-9.

23. Boora F, Chirisa $E$, Mukanganyama $S$. Evaluation of nitrite radical scavenging properties of selected Zimbabwean plant extracts and their phytoconstituents. Journal of Food Processing. 2014;1-7.

\section{GRAPHICAL ABSTRACT}

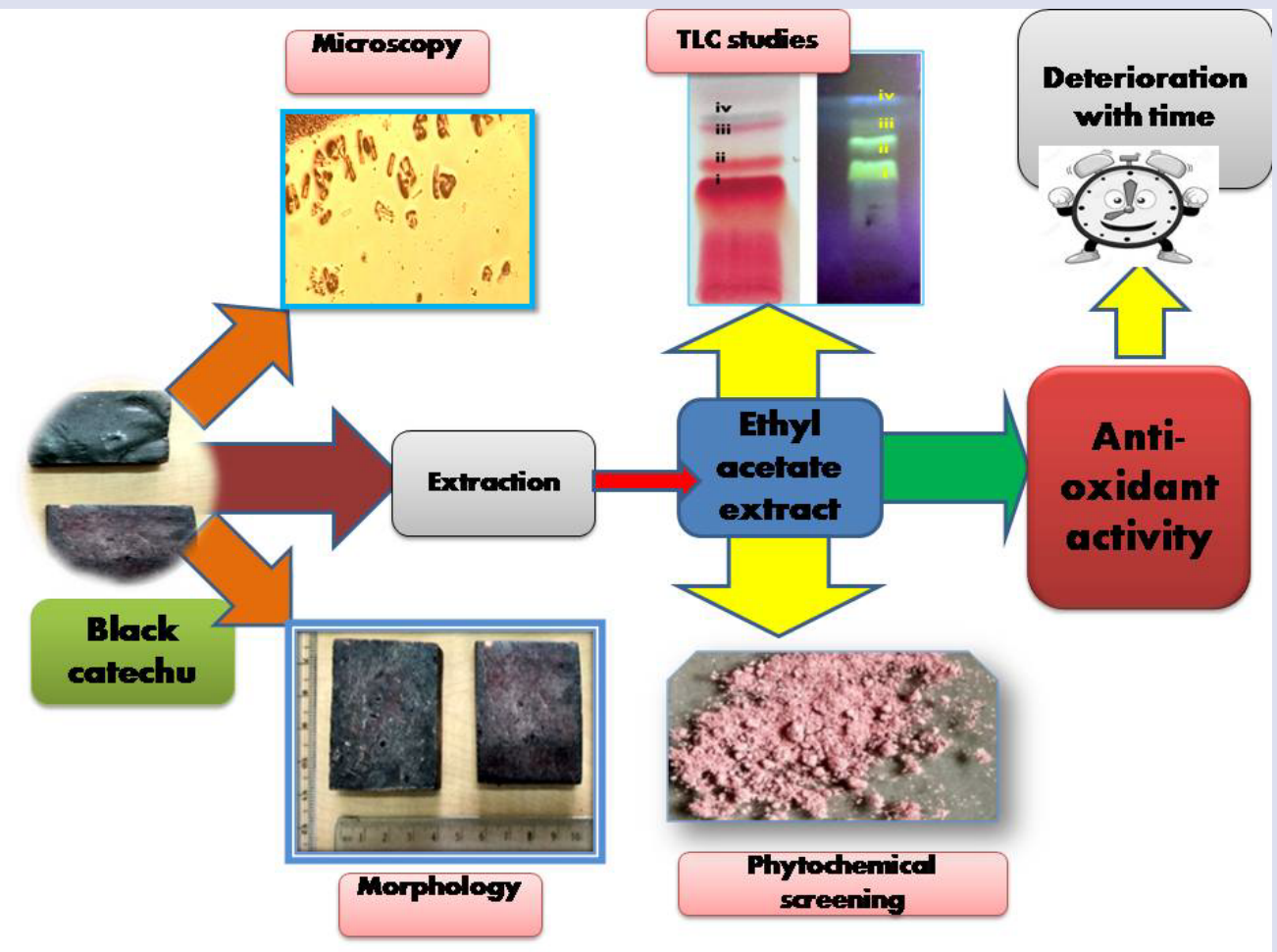

\section{ABOUT AUTHORS}

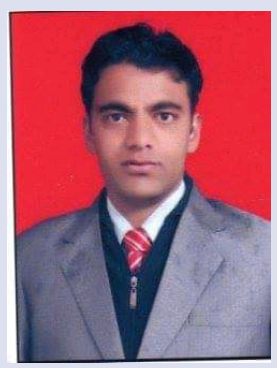

Mr. Pankaj Sharma is a P.hD Research Scholar in SJJT University, Rajasthan (India). His current area of Research is design and development of Phytosomes of herbal drug containing polyphenolic \& flavonoids.

Cite this article: Sharma P. Investigation on Photodecomposition of Standardised Ethyl Acetate Fraction of Katha. Pharmacogn J. 2020;12(4):815-20. 